Results Of the 156 specimens, 83 N. gonorrhoeae strains were tested for antimicrobial susceptibilities to 18 agents. The prevalence of $\beta$-lactamase producing strains and chromosomally-mediated resistant strains were $7.2 \%$ and $16.5 \%$, respectively. Against cepharosporins, one strain was resistant to cefixime with MIC $0.5 \mu \mathrm{g} / \mathrm{ml}$. There was not resistant strain to ceftriaxone, but the 7 strains (8.4\%) had MIC $0.125 \mu \mathrm{g} / \mathrm{ml}$. The MIC of fluoroquinolones to all strains showed a bimodal distribution. The values of MIC90 of ciprofloxacin and levofloxacin were 16 and $8 \mu \mathrm{g} / \mathrm{ml}$, respectively. Sitafloxacin, one of fluoroquinolones had strong activity to $\mathrm{N}$. gonorrhoeae strains and the value of MIC90 was $0.25 \mu \mathrm{g} / \mathrm{ml}$. The MIC of azithromycin in 2 strains was $2 \mu \mathrm{g} / \mathrm{ml}$, but no high-level resistance to macrolides was detected.

Conclusion The first national surveillance for antimicrobial susceptibilities of $N$. gonorrhoeae was performed. Fluoroquinolone-resistance $N$. gonorrhoeae strains were spread in Japan. The resistant rate of azithromycin resistant was $2.4 \%$.

\section{P2.082 POST-TREATMENT DETECTION OF AZITHROMYCIN IN HIGH- VAGINAL SWABS USING LIOUID CHROMATOGRAPHY AND TANDEM MASS SPECTROMETRY (LC-MS/MS)}

doi:10.1136/sextrans-2013-051184.0346

\begin{abstract}
1.2 L A Vodstrcil, ${ }^{3} \mathrm{~T}$ Rupasinghe, ${ }^{3} \mathrm{D}$ Tull, ${ }^{1,4} \mathrm{~K}$ Worthington, ${ }^{1,4} \mathrm{M} \mathrm{Y}$ Chen, ${ }^{5} \mathrm{~W}$ M Huston, ${ }_{1,4} \mathrm{C}$ K Fairley, ${ }^{3} \mathrm{M}$ McConville, ${ }^{2,6,7} \mathrm{~S} N$ Tabrizi, ' J S Hocking. 'Melbourne School of Population and Global Health, University of Melbourne, Parkville, Australia; ${ }^{2}$ Murdoch Children's Research Institute, Parkville, Australia; ${ }^{3}$ Metabolomics Australia, Bio21 Institute, University of Melbourne, Parkville, Australia; ${ }^{4}$ Melbourne Sexual Health Centre, Carlton, Austria; ${ }^{5}$ Faculty of Health - Biomedical Sciences, Institute of Health and Biomedical Innovation, Queensland University of Technology, Brisbane, Australia; ${ }^{6}$ Department of Microbiology and Infectious Diseases, The Royal Women's Hospital, Parkville, Australia; 'Department of Obstetrics and Gynaecology, University of Melbourne, Parkville, Australia
\end{abstract}

Introduction Recent data have raised questions over the efficacy of azithromycin $1 \mathrm{~g}$ for the treatment of chlamydia infection. In order to measure effective absorption, we developed a protocol to quantify the concentration of azithromycin using liquid chromatography and tandem mass spectrometry (LC-MS/MS) in self-collected high-vaginal swabs.

Methods Ten healthy women were asked to self-collect a highvaginal swab (baseline) prior to taking a $1 \mathrm{~g}$ dose of azithromycin. A blood sample was collected four hours later to determine plasma concentrations of azithromycin. Participants then self-collected a high vaginal swab each day for a further 9 days. All swabs were preserved in $1 \mathrm{ml}$ of $100 \%$ Methanol and stored at $-80^{\circ} \mathrm{C}$ prior to analysis. One $\mathrm{ml}$ of chloroform containing $10 \mathrm{mg} / \mathrm{ml}$ of Leucine enkephalin as an internal standard was added to extract azithromycin. Azithromycin concentrations were calculated using a validated LC-MS/MS method. Data were normalised to the internal standard and to membrane lipid concentrations, measured in the same samples using LC-MS/MS.

Results Azithromycin was detected at varying concentrations in all 10 women in all post-treatment samples. The highest average normalised azithromycin concentration of $953 \mathrm{ng} / \mathrm{ml}$ (range $=267-$ $2200 \mathrm{ng} / \mathrm{ml}$, standard error of mean $(\mathrm{sem})=181 \mathrm{ng} / \mathrm{ml}$ ) was detected on day 2 post-treatment. The lowest average azithromycin concentration was $164 \mathrm{ng} / \mathrm{ml}$ (range $=51-387 \mathrm{ng} / \mathrm{ml}$, sem $=42 \mathrm{ng} / \mathrm{ml}$ ), 9 days post-treatment. The average concentration of azithromycin detected in blood samples was 339ng/ml (range $=107-628 \mathrm{ng} / \mathrm{ml}$, sem $=57 \mathrm{ng} / \mathrm{ml}$ ). In $9 / 10$ women azithromycin concentrations remained above $64 \mathrm{ng} / \mathrm{ml}$, the hypothesised mean inhibitory concentration (MIC) of azithromycin for chlamydia, for the entire 9 days.

Conclusion We have validated a method for detecting the azithromycin concentration in self-collected high-vaginal samples using LC-MS/MS. Azithromycin concentrations remained above the reported MIC of $64 \mathrm{ng} / \mathrm{ml}$ for up to 9 days post-treatment in highvaginal swabs from 10 healthy women.

\section{P2.083 A COMPARATIVE EFFICACY OF NIFURATEL AND METRONIDAZOLE IN THERAPY OF BACTERIAL VAGINOSIS ASSOCIATED WITH ATOPOBIUM VAGINAE}

doi:10.1136/sextrans-2013-051184.0347

'Y Perlamutrov, ${ }^{1} \mathrm{M}$ Gomberg, ${ }^{1} \mathrm{~N}$ Chernova, ${ }^{1} 0$ Bochkova, ${ }^{2} \mathrm{~S}$ Shcherbo. ${ }^{1} \mathrm{Moscow}$ State University of Medicine and Dentistry, Moscow, Russian Federation; ${ }^{2}$ N.I. Pirogov Russian State Medical University, Moscow, Russian Federation

Purpose To evaluate the efficacy of nifuratel plus nystatin combination in the treatment of patients with bacterial vaginosis (BV) associated with $A$. vaginae.

Methods A prospective comparative study on the clinical efficacy, safety and tolerability of nifuratel plus nystatin combination was performed in patients with A. vaginae-associated BV. A total of 197 women meeting the inclusion/exclusion criteria and 20 healthy women (the control group) were examined. BV was diagnosed in 148 out of 197 women with vaginal discharge (according to Amsel criteria). The diagnosis of BV was not confirmed in 49 patients and they were excluded from the study. Patients were randomised to receive intravaginal treatment with suppositories containing a combination of nifuratel $(500 \mathrm{mg})$ and nystatin (200,000 IU) at night for 8 days (group 1) or standard treatment with suppositories containing metronidazole $(500 \mathrm{mg}$ ) twice daily (in the morning and at night) for 10 consecutive days (group 2). Treatment results in both groups were compared one week after the end of therapy. Control test of cure with respect to $A$. vaginae was carried out by PCR one month after the end of therapy.

Results PCR assay detected A. vaginae in 83 (56\%) out of 148 BV cases and in none from the control group $(p<0.01)$. In patients with A. vaginae-associated BV efficacy of the nifuratel plus nystatin combination was $90.3 \%$, while standard metronidazole therapy was ineffective (cure in only $10 \%$ of cases).

Conclusion A. vaginae may be an additional marker of BV. Combination of nifuratel with nystatin was much more effective than standard intravaginal administration of metronidazole in the treatment of $A$. vaginae-associated BV.

\section{P2.084 A CASE OF RAPID CLEARANCE OF PENILE BOWENOID PAPULOSIS WITH IMIQUIMOD CREAM}

doi:10.1136/sextrans-2013-051184.0348

W Tan, G Ong. National Skin Centre, singapore, Singapore

Introduction Bowenoid papulosis is a form of penile intraepithelial neoplasia associated with the oncogenic human papilloma virus (HPV) strains 16, 18, 31 and 33. It occurs in young sexually active patients and has a low risk of progressing to invasive squamous cell carcinoma.

Case report The patient was a 31 year old chinese male who presented with a 3 month pruritic rash over his glans penis. Previous treatment with hydrocortisone cream had caused more lesions to appear and was stopped.

On examination, there were multiple erythematous discrete papules over the glans penis and a cluster of papules at the inner prepuce. A skin biopsy was consistent with bowenoid papulosis showing a thickened epidermis with full thickness atypical keratinocytes with loss of normal polarity. A band like infiltrate of lymphocytes, plasma cells and eosinophils was present within the dermis. The rest of his sexually transmitted infection screen including syphilis serology and human immunodeficiency virus tests were negative.

He was started on topical imiquimod three applications per week and noted complete clearance of the prepuce lesions after two 